\title{
Impact of Glucose Fluctuation on Acute Cerebral Infarction in Type 2 Diabetes
}

\author{
Jinxin Huang, Xingguang Zhang, Juan Li, Liya Tang, Xiumin Jiao, Xiaofeng Lv
}

\begin{abstract}
Objective: This study aimed to describe the frequency and temporal profile of acute cerebral infarction (ACI) using a continuous glucose monitoring system (CGMS) in patients with and without type 2 diabetes mellitus (T2DM) and explore the impact of blood glucose fluctuations on the short-term prognosis of ACI. Methods: The subjects were divided into four groups: T2DM with acute cerebral infarction (DMCI, Group A, n=56); T2DM without acute cerebral infarction (DM-NCI, Group B, n=36); Acute cerebral infarction patients without T2DM (NDM-CI, Group C, $n=54$ ); Healthy control group (NG, Group D, $n=36$ ). The National Institutes of Health Stoke Scale (NIHSS) and modified Rankin scale (mRs) were collected in Group A and C. All subjects were monitored for 72 hours using the CGMS. Indices such as fasting blood glucose (FBG) and mean amplitude of glycemic excursions (MAGE) were calculated. Glycemic excursions were compared between Group A, B, C and Group D, respectively. Multiple linear regression analysis and logistic analysis was applied. Results: MAGE is related to NIHSS, homocysteine (HCY), HOMA-IR, FBG, CRP and IMT, while NIHSS is related to CRP, HCY, HOMA-IR, IMT. The factors impacting the short-term prognosis of ACI were NIHSS, HBA1C and MAGE. Conclusion: Larger glucose fluctuations are associated with more stroke risk factors and are associated with a poorer shortterm prognosis. More attention should be paid to glucose fluctuations in patients with ACI and a history of T2DM.
\end{abstract}

RÉSUMÉ: Impact des fluctuations de la glycémie sur l'infarctus cérébral aigu dans le diabète de type 2. Objectif : Le but de l'étude était de décrire la fréquence et le profil temporel de l'infarctus cérébral aigu (ICA) au moyen d'un système de surveillance continue de la glycémie (SSCG) chez les patients avec et sans diabète de type 2 (DT2) et d'examiner l'impact des fluctuations de la glycémie sur le pronostic à court terme de l'ICA. Méthode : Les sujets ont été divisés en 4 groupes : DT2 avec ICA (groupe A, DIC; $\mathrm{n}=56$ ) ; DT2 sans ICA (groupe B, DNIC ; $\mathrm{n}=36$ ) ; ICA sans DT2 (groupe $\mathrm{C}, \mathrm{ND}-\mathrm{IC} ; \mathrm{n}=54$ ) ; groupe témoin en santé (groupe $\mathrm{D}, \mathrm{GN}: \mathrm{n}=36$ ). Nous avons recueilli le score au National Institutes of Health Stroke Scale (NIHSS) et à l'échelle modifiée de Rankin chez les sujets des groupes A et C. Le système de surveillance continue du glucose a été laissé en place pendant 72 heures chez tous les sujets. Le taux de glycémie à jeun (GJ) et l'amplitude moyenne des excursions glycémiques (AMEG) ont été calculés. Les excursions glycémiques ont été comparées entre les groupes A, B, C et D respectivement. L'analyse de régression linéaire multiple et l'analyse logistique ont été utilisées pour analyser les données. L'AMEG est liée au score du NIHSS, à l'homocystéine (HCY), au HOMA-IR, à la GJ, à la CRP et à l'IMT, alors que le NIHSS est lié au CRP, à l'HCY, à l'HOMA-IR, à l'IMT. Les facteurs qui influencent le pronostic à court terme de l'ICA étaient le NIHSS, l'HBA1C et l'AMEG. Conclusion : Des fluctuations glycémiques plus considérables sont associées à de plus nombreux facteurs de risque de l'accident vasculaire cérébral et également au pronostic à court terme. Nous devrions porter plus d'attention aux fluctuations glycémiques qu'à l'histoire de diabète chez les patients atteints d'un ICA.

Can J Neurol Sci. 2014; 41: 486-492

The incidence of type 2 diabetes mellitus (T2DM) is increasing. In China, Yang et al reported that the prevalence of diabetes in adults over 20 years-of-age was $9.7 \%$, and the prevalence of pre-diabetes (impaired fasting glycaemia and impaired glucose tolerance) has reached $15.5 \%{ }^{1}$. Diabetes is a proven risk factor for stroke ${ }^{2-4}$, with a two-to-three fold increased risk for diabetic patients compared with non-diabetic patients. Numerous studies provide persuading evidence of the deleterious effects of hyperglycemia on the injured brain in stroke ${ }^{5-7}$. Besides increased cardiovascular complications, immune-depression syndrome, altered cerebral perfusion or secondary brain injury caused by inflammation and hyperglycemia also may play an important role $^{8,9}$. The glycosylated hemoglobin (HbAIc) was established by studies such as the diabetes control and complications trial (DCCT) and
British prospective diabetes study (UKPDS) as predictors of diabetic chronic complications. However, the same HbAlc level did not reflect the same risk of complications ${ }^{10}$.

Unstable hyperglycemia or glucose fluctuations, put a significant demand on the glands responsible for regulating glucose levels. Several studies have reported that diabetes complications increased more in proportion to post-meal glucose

From the Beijing Military General Hospital, No. 5 Nan Men Cang, Dongcheng district, Beijing, China.

Received October 29, 2013. Final Revisions Submitted February 5, 2014 Correspondence to: Xiaofeng Lv, Beijing Military General Hospital, No. 5 Nan Men Cang, Dongcheng district, Beijing 100700, China. Email: xiaofenglv7966@163.com. 
or peak glucose levels, rather than average blood glucose levels. This was more evident in cardiovascular diseases that account for the largest proportion of mortality in diabetes patients ${ }^{11-13}$. We speculated that in addition to HbAIc, glucose fluctuations may become another indicator of blood glucose control which may affect the occurrence of blood vessel related complications. Quagliaro et al determined that the blood vessel endothelium was damaged more by blood glucose fluctuations than by chronic persistent hyperglycemia ${ }^{14}$. Despite the increasing awareness of the impact of hyperglycemia on stroke and the detrimental effects upon stroke outcomes, few studies have examined, in detail, glucose profiles through the use of dynamic glucose monitoring and determined possible advantages of dynamic glucose monitoring in determining the prognosis following stroke.

The aim of our study was to explore the impact of glucose fluctuation on the short-term prognosis of acute cerebral infarction in T2DM patients. The National Institutes of Health Stroke Scale (NIHSS) ${ }^{15}$ and the modified Rankin scale (mRs) are documented parameters of stroke severity and short-term outcome $^{16}$. In our study, they were used to estimate the severity and short-term prognosis of cerebrovascular and neurologic impairment in T2DM patients and acute cerebral infarction patients without T2DM.

\section{Patients And Methods}

\section{Subjects and grouping}

The study was approved and registered by our hospital Ethics Committee in August 2012. The Ethics committee of Beijing Military General Hospital approved relating screening, treatment and data collection of these patients. Written informed consent was obtained from each patient for the use of their blood sample and clinical information. All work was undertaken following the provisions of the Declaration of Helsinki.

A total of 110 patients with acute cerebral infarction (ACI) were recruited from the cardiovascular outpatient unit of our hospital. The inclusion criteria of these ACI patients were: 1) having symptoms of onset of ACI within 24 hours (h) preceding admission; 2) diagnosed by magnetic resonance imaging (MRI) or computed tomogram (CT) according to 1995 acute cerebral infarction diagnosis standards promulgated by the Fourth National Cerebrovascular Disease Conference ${ }^{17}$; 3 ) The TOAST classification of Large-Artery Atherosclerosis (LAA) was used to define cerebral infarction.

Acute cerebral infarction patients were excluded if they had: 1) Neurological deficit proved to be of non-ischemic origin, such as hemorrhagic stroke; 2) Transient ischemic attack; 3) Cerebral tumor and cerebral infarction onset time was unknown; All the recruited ACI patients were then divided into two groups: patients with T2DM (Group A) and patients without T2DM (Group C).

Besides the ACI patients, T2DM patients without ACI were recruited as Group B. The diagnosis of T2DM patients were followed the (World Health Organization) WHO diagnostic criteria of type two diabetes mellitus in $1999^{18}$. Healthy individuals without diabetes mellitus and coronary artery disease were recruited from volunteer of community inhabitants in Beijing (matched in age), they were set as normal control group
(Group D). Recruited subjects of Group D did not receive any medication two weeks before they were recruited; Patients from Group A, B and C did not change any anti-coagulant, antidiabetic drugs, anti-hypertensive or lipid-lowering therapy before they were recruited.

All the subjects were excluded if they possessed the following characteristics: 4) Severe infection; 5) Known cardiovascular artery disease; 6) Symptomatic heart failure; 7) Objective inability to perform treadmill exercise; 8) Known or active malignancy, advanced renal failure (clearance $<25$ $\mathrm{ml} / \mathrm{mi} / 1.73 \mathrm{~m}^{2}$ ); 9) liver cirrhosis (child Pugh III); 10) In treatment for other diseases requiring glucocorticoid treatment; 11) and patients with other diseases affecting the metabolism of glucose and therapy measures (such as infusion of glucose liquid).

\section{Treatment and demographic data}

In accordance with the "Guide for cerebrovascular disease prevention and treatment suggestion in China"; all ACI patients were given corresponding active treatment to avoid receiving intravenous fluids containing glucose. Insulin was given to ACI patients when their blood glucose increased more than 11.1 $\mathrm{mmoI} / \mathrm{L}$, and their blood glucose was controlled under 8.3 $\mathrm{mmoI} / \mathrm{L}$. Oral glucose-lowering treatment was given to other T2DM patients (with or without ACI).

Demographic and general clinical data such as the gender, age, body mass index (BMI), systolic pressure (SBP), high density lipoprotein cholesterol (HDL-c), low density lipoprotein cholesterol (LDL-c), triglyceride (TG), total cholesterol (TC), $\mathrm{HbA1c}, \mathrm{C}$ reactive protein (CRP), carotid intima-media thickness (CIMT), homocysteine (HCY), fibrinogen, of all subjects were recorded. The NIHSS and mRs were collected in patients from Group A and $\mathrm{C}$ at the time of admission and two weeks after admission. Modified Rankin scores from 0 to 2 were recorded as level 0 and $\mathrm{mRs}$ from 3 to 5 were recorded as level 1 .

\section{Dynamic blood glucose fluctuation monitoring}

The insulin resistance index (HOMA-IR) was calculated with the homeostasis model assessment. HOMA-IR= fasting blood glucose $(\mathrm{FBG}) \times$ fasting insulin $\left(\right.$ FINS) $/ 22.5^{16}$.

Continuous glucose monitoring system (CGMS) was applied on all the subjects for $72 \mathrm{~h}$. The glucose standard deviation (SD), the average amplitude of glycemic excursions (MAGE), the absolute means of daily differences (MODD) were recorded separately. The MAGE was calculated by measuring the arithmetic mean of the differences between consecutive peaks and nadirs, provided that the differences were greater than one $\mathrm{SD}$ of the mean glucose value. The MODD was calculated as the mean of the absolute differences between glucose values at the same time of two consecutive days.

Glycemic excursions were compared between Group A, B, C and D. The key factors impacting on modified $\mathrm{mRs}$ were analyzed in all subjects by logistic regression analysis. The correlations between NIHSS and mRs at the time of admission and two weeks after admission were analyzed. 
Table 1: Comparison of the indexes among the four groups

\begin{tabular}{|c|c|c|c|c|}
\hline Group & $\operatorname{DMCI}(\mathrm{A})$ & DMNCI (B) & NDMCI (C) & Group (D) \\
\hline Number & $\mathrm{n}=56$ & $\mathrm{n}=36$ & $\mathrm{n}=54$ & $\mathrm{n}=36$ \\
\hline $\operatorname{Sex}(M / F)$ & $30 / 26$ & $18 / 18$ & $36 / 18$ & $18 / 18$ \\
\hline Age (year) & $65.04 \pm 11.51$ & $64.67 \pm 11.47$ & $63.63 \pm 12.17$ & $63.80 \pm 12.02$ \\
\hline History of hypertension (\%) & $44 / 56(78.57 \%)^{\# \Delta}$ & $32 / 36(88.88 \%)$ & $18 / 54(33.33 \%)$ & 0 \\
\hline History of hyperlipidemia (\%) & $44 / 56(78.57 \%)^{\# \Delta}$ & $24 / 36(66.67 \%)$ & $20 / 54(37.03 \%)$ & 0 \\
\hline History of stroke (\%) & $34 / 56(60.71 \%)^{\# \Delta}$ & $10 / 36(27.77 \%)$ & $18 / 54(33.33 \%)$ & 0 \\
\hline SBP (mmHg) & $151.71 \pm 20.98^{* \#}$ & $133.33 \pm 18.06^{*} \Delta$ & $145.15 \pm 18.48^{*}$ & $126.28 \pm 12.96$ \\
\hline FBG $(\mathrm{mmol} / \mathrm{l})$ & $9.28 \pm 3.23^{*}$ & $11.11 \pm 3.94^{*} \triangle$ & $5.51 \pm 1.19$ & $5.43 \pm 0.98$ \\
\hline 2hPG (mmol/l) & $12.1(10.37,13.72)^{* \# \Delta}$ & $15.1(11.86,16.53)^{* \Delta}$ & $7.0(6.1,8.1)$ & $6.95(6.0,7.4)$ \\
\hline MAGE (mmol/l) & $8.69 \pm 3.62^{* \# \Delta}$ & $6.96 \pm 2.96^{*} \triangle$ & $4.75 \pm 1.91^{*}$ & $1.53 \pm 0.46$ \\
\hline $\mathrm{SDBG}(\mathrm{mmol} / \mathrm{l})$ & $2.90 \pm 0.73^{* \# \Delta}$ & $2.78 \pm 1.21^{*} \Delta$ & $1.89 \pm 0.81^{*}$ & $0.60 \pm 0.20$ \\
\hline MODD (mmol/l) & $2.88 \pm 0.70^{*} \triangle$ & $2.80 \pm 1.26^{*} \triangle$ & $1.67 \pm 0.75^{*}$ & $0.49 \pm 0.27$ \\
\hline HBA1C (\%) & $8.62 \pm 1.75^{* \# \Delta}$ & $9.89 \pm 2.53^{*} \triangle$ & $5.9 \pm 0.61$ & $5.82 \pm 0.57$ \\
\hline $\mathrm{TC}(\mathrm{mmol} / \mathrm{l})$ & $4.74(4.07,5.55)^{*}$ & $4.66(4.05,5.78)^{*}$ & $4.11(3.34,5.10)$ & $4.11(3.07,5.31)$ \\
\hline TG (mmol/l) & $2.74 \pm 1.12^{*}$ & $2.98 \pm 1.75^{*}$ & $1.38 \pm 0.79^{*}$ & $1.01 \pm 0.41$ \\
\hline LDL(mmol/l) & $3.13 \pm 0.98^{*}$ & $3.06 \pm 1.02^{*}$ & $2.76 \pm 1.05^{*}$ & $2.07 \pm 0.47$ \\
\hline CRP (mg/l) & $8.78 \pm 1.36^{* \# \Delta}$ & $4.85 \pm 2.83^{*}$ & $4.54 \pm 2.59^{*}$ & $1.86 \pm 0.53$ \\
\hline Fibrinogen (g/l) & $2.93 \pm 0.62^{* \#}$ & $3.25 \pm 0.64^{*} \triangle$ & $2.70 \pm 0.57$ & $2.86 \pm 0.53$ \\
\hline Homocysteine (umol/l) & $16.51 \pm 12.21^{* \triangle}$ & $15.16 \pm 6.11^{* \triangle}$ & $25.21 \pm 14.79^{*}$ & $11.71 \pm 2.69$ \\
\hline Fasting insulin (mIU/l) & $13.59 \pm 9.95^{* \#}$ & $29.98 \pm 15.38^{*} \triangle$ & $9.40 \pm 6.46$ & $8.31 \pm 4.71$ \\
\hline HOMA-IR & $6.10 \pm 4.94^{*} \triangle$ & $13.62 \pm 3.82^{*}$ & $3.01 \pm 1.61^{*}$ & $2.07 \pm 1.02$ \\
\hline
\end{tabular}

*Compared with Group D, p $<0.05$; \#compared with Group B, p<0.05; ${ }^{\Delta}$ compared with Group C, p $<0.05$.

\section{Statistical analysis}

If the data were normal distribution data, t-test was used for comparison between two groups and single factor analysis of variance was used in comparison in four groups. If the data were non-normal distribution data, rank sum test was used for comparison between two groups and Kruskal-Wallis analysis was used for comparison of four groups. Chi-square test was used for qualitative data testing; with all the variables investigated (continuous variables and the binary classification variables) as a relevant variable, $\mathrm{mRs}$ score as the dependent variable for Logistic regression to analyze the short-term prognosis of cerebral infarction risk factors. All analyses were performed using SPSS software program version 16.0 for Windows (SPSS Institute Inc.). $\mathrm{P}<0.05$ was considered as statistically significant.

\section{RESULTS}

The age, gender and other demographic data are shown in Table 1. There is no significant difference between age distribution and gender among all the groups.

\section{Comparison of the indexes among the four groups}

Table 1 shows the detailed data of the four groups. Compared with Group D (healthy control), patients from Group C had significantly higher SBP (145.15 \pm 18.48 versus (vs) $126.28 \pm$ 
Table 2: The Linear correlation analysis between MAGE/NIHSS and relative factors in Group A and C

\begin{tabular}{lll}
\hline Group & DMCI & NDMCI \\
\hline $\mathrm{N}$ & 56 & 54 \\
NIHSS (0 day) & $15.32 \pm 4.07^{*}$ & $14.54 \pm 6.42$ \\
NIHSS (14 day) & $10.32 \pm 3.23^{* *}$ & $7.54 \pm 3.60$ \\
$\mathrm{mRS}(0 / 1)$ & $14 / 42^{* *}$ & $34 / 20$ \\
\hline
\end{tabular}

$* \mathrm{p}<0.05, * * \mathrm{p}<0.01$

12.96, mmHg), TG $(1.38 \pm 0.79$ vs $1.01 \pm 0.41, \mathrm{mmol} / \mathrm{l})$, LDL-c $(2.76 \pm 1.05$ vs $2.07 \pm 0.47, \mathrm{mmol} / \mathrm{l})$, MAGE $(4.75 \pm 1.91$ vs $1.53 \pm 0.46, \mathrm{mmol} / 1)$, SDBG $(1.89 \pm 0.81 \mathrm{vs} 0.60 \pm 0.20, \mathrm{mmol} / \mathrm{l})$, MODD (1.67 \pm 0.75 vs $0.49 \pm 0.27, \mathrm{mmol} / \mathrm{l})$, CIMT (1.0 vs 0.7, $\mathrm{mm}), \mathrm{CRP}(4.54 \pm 2.59$ vs $1.86 \pm 0.53, \mathrm{mg} / \mathrm{l}), \mathrm{HCY}(25.21 \pm 14.79$ vs $11.71 \pm 2.69$, umol/1), HOMA-IR value $(3.01 \pm 1.61$ vs $2.07 \pm 1.02)(P>0.05)$. Although Group $B$ and $C$ have the same trends compared with Group D, Group B had higher FBG, $2 \mathrm{~h}$ PG, HbA1C, CIMT, fasting insulin, fibrinogen and TC value when compared with Group $\mathrm{C}(\mathrm{P}<0.05)$. Compared with patients from Group C, patients from Group A had significantly higher hypertension rate $(78.57 \%$ vs $33.33 \%)$, hyperlipidemia rate (78.57\% vs $37.03 \%)$, stroke history rate $(60.71 \%$ vs $33.33 \%), 2 \mathrm{~h}$

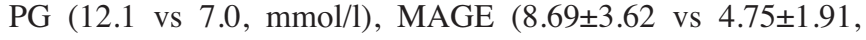
$\mathrm{mmol} / \mathrm{l}), \operatorname{SDBG}(2.90 \pm 0.73$ vs $1.89 \pm 0.81, \mathrm{mmol} / \mathrm{l}), \mathrm{MODD}$ $(2.88 \pm 0.70$ vs $1.67 \pm 0.75, \mathrm{mmol} / \mathrm{l}), \mathrm{HbA1C}(8.62 \pm 1.75$ vs $5.9 \pm 0.61, \%)$, CRP $(8.78 \pm 1.36$ vs $4.54 \pm 2.59, \mathrm{mg} / \mathrm{l}), \mathrm{HCY}$ $(16.51 \pm 12.21$ vs $25.21 \pm 14.79$, umol/l), and HOMA-IR value $(6.10 \pm 4.94$ vs $3.01 \pm 1.61)(\mathrm{P}<0.05)$. Compared with Group B, Group A had the higher parameters in hypertension rate, hyperlipidemia rate, acute cerebral infarction history rate, $2 \mathrm{~h}$ PG, MAGE, SDBG, MODD, HbA1C, CRP, SBP, but lower fasting insulin $(13.59 \pm 9.95$ vs $29.98 \pm 15.38, \mathrm{mIU} / \mathrm{l})$ value $(\mathrm{P}<0.05)$.

\section{Linear correlation analysis between MAGE/NIHSS and} relative factors in Group A and C

Multiple linear regression analysis showed MAGE were significantly correlated with NIHSS, HCY, HOMA-IR, FBG, CRP, $(\mathrm{r}=0.596,0.179,-0.183,0.495,0.239, \mathrm{P}<0.05)$. While NIHSS were correlated with CRP, HCY, HOMA-IR, ( $r=0.343$, $0.292,-0.203, \mathrm{P}<0.05)$. Fourteen days after admission, NIHSS and $\mathrm{mRs}$ scores in Group A were higher than Group C $(\mathrm{P}<0.05)$ (Table 2).

\section{Clinical baseline comparison of different levels of MAGE in ACI patients}

All ACI patients included were divided into two groups according to the fluctuation of blood MAGE levels (3.9 mmol/1 was used as the point of tangency). The high level of MAGE group (3.9 or higher tendency) in patients with ACI (high MAGE - ACI group) had a higher hypertension rate, hyperlipidemia rate, acute cerebral infarction history rate compared with the low MAGE level group ( $<3.9$ tendency) in patients with ACI (low MAGE - ACI group) $(\mathrm{p}<0.01)$; the high MAGE - ACI group had significantly higher FBG, HbA1C, NIHSS score, fasting insulin, HOMA-IR and HCY level than low MAGE - ACI group; 14 days after admission, mRS score of high MAGE - ACI group were higher than the low MAGE - ACI group; The differences are statistically significant. $(\mathrm{p}<0.01)$ (Table 3$)$.

\section{Clinical baseline comparison of different levels of MAGE in ACI patients}

All ACI patients were divided into two groups according to whether had a history of diabetes mellitus (DM). Each group was

Table 3: Clinical baseline comparison of different levels of MAGE in ACI patients

\begin{tabular}{|c|c|c|c|c|c|c|c|c|}
\hline Group & $\begin{array}{l}\text { History of hypertension } \\
(\mathrm{Y} / \mathrm{N})\end{array}$ & \multicolumn{2}{|c|}{$\begin{array}{l}\text { History of stroke } \\
(\mathrm{Y} / \mathrm{N})\end{array}$} & $\begin{array}{l}\text { MAGE } \\
(\mathrm{mmol} / \mathrm{l})\end{array}$ & $\begin{array}{l}\text { SDBG } \\
(\mathrm{mmol} / \mathrm{l})\end{array}$ & $\begin{array}{l}\text { MODD } \\
(\mathrm{mmol} / \mathrm{l})\end{array}$ & $\begin{array}{l}\text { HBA1C } \\
(\%)\end{array}$ & $\begin{array}{l}\text { NIHSS } \\
\text { (score) }\end{array}$ \\
\hline High MAGE-ACI & $56 / 26$ & $46 / 36$ & & $6.83 \pm 2.50$ & $2.58 \pm 0.71$ & $2.44 \pm 0.75$ & $7.68 \pm 1.90$ & $10.63 \pm 4.77$ \\
\hline Low MAGE-ACI & $6 / 22$ & $6 / 22$ & & $2.52 \pm 0.95$ & $1.16 \pm 0.55$ & $1.43 \pm 0.73$ & $5.80 \pm 0.96$ & $7.29 \pm 2.81$ \\
\hline $\mathrm{T} / \mathrm{X} 2$ & 9.31 & 5.03 & & 6.25 & 6.76 & 4.37 & 3.38 & 2.47 \\
\hline $\mathrm{P}$ & 0.00 & 0.02 & & 0.00 & 0.00 & 0.00 & 0.00 & 0.01 \\
\hline Group & $\begin{array}{l}\text { History of hyperlipidemia } \\
(\mathrm{Y} / \mathrm{N})\end{array}$ & $\begin{array}{l}\mathrm{mRs} \\
(0 / 1)\end{array}$ & $\begin{array}{l}\text { FBG } \\
(\mathrm{mmol} / \mathrm{l})\end{array}$ & $\begin{array}{l}\text { CRP } \\
(\mathrm{mg} / 1)\end{array}$ & $\begin{array}{l}\text { Homo } \\
(\mu \mathrm{mol}\end{array}$ & teine & $\begin{array}{l}\text { Fasting insulin } \\
(\mathrm{mIU} / \mathrm{l})\end{array}$ & HOMA-IR \\
\hline High MAGE-ACI & $54 / 28$ & $26 / 56$ & $8.08 \pm 3.20$ & $9.79 \pm 7.62$ & $23.91=$ & .99 & $13.16 \pm 9.24$ & $5.06 \pm 3.25$ \\
\hline Low MAGE-ACI & $10 / 18$ & $22 / 6$ & $5.52 \pm 1.61$ & $2.01 \pm 1.07$ & 11.65 & & $6.75 \pm 3.42$ & $2.04 \pm 1.12$ \\
\hline $\mathrm{T} / \mathrm{X} 2$ & 3.89 & 9.31 & 2.85 & 2.12 & 3.00 & & 2.52 & 2.12 \\
\hline $\mathrm{P}$ & 0.04 & 0.00 & 0.01 & 0.03 & 0.00 & & 0.01 & 0.03 \\
\hline
\end{tabular}




\begin{tabular}{|c|c|c|c|c|}
\hline \multirow[t]{2}{*}{ Group } & \multicolumn{2}{|c|}{ MAGE (mmol/l) } & \multirow[t]{2}{*}{$x^{2}$} & \multirow[t]{2}{*}{$\mathrm{P}$} \\
\hline & High MAGE (mRS $(0 / 1))$ & Low MAGE (mRS $(0 / 1))$ & & \\
\hline With DM ( $\mathrm{n}=56)$ & $8 / 38$ & $6 / 4$ & 3.97 & 0.04 \\
\hline Without DM $(\mathrm{n}=54)$ & $18 / 18$ & $16 / 2$ & 3.89 & 0.04 \\
\hline
\end{tabular}

$\begin{aligned} & \text { Table 5: The multi-factor Logistic regression analysis of short-term prognosis in patients } \\
& \text { with ACI }\end{aligned}$
\begin{tabular}{llllllll} 
Step & B & SE & Wald & Sig & Exp (B) & \multicolumn{2}{c}{$95 \%$ CI for EXP (B) } \\
\hline Constant & -11.767 & 3.761 & 9.788 & 0.002 & - & - & CI \\
NIHSS & 1.137 & 0.391 & 8.470 & 0.004 & 3.116 & 1.449 & 6.701 \\
HBA1C & 0.795 & 0.365 & 4.738 & 0.029 & 2.213 & 1.082 & 4.626 \\
MAGE & 0.395 & 0.214 & 3.212 & 0.048 & 1.461 & 0.965 & 2.248 \\
\hline
\end{tabular}

divided into two subgroups again on the basis of MAGE level. In DM-ACI group, mRS scores of the subgroup with high MAGE level were higher than in the low MAGE level subgroup. The two subgroups were statistically different; in the non-DM ACI group, mRS score of patients with high levels of MAGE were significantly higher than in the low MAGE level subgroup $(\mathrm{p}<0.05))($ Table 4).

The multi-factor Logistic regression analysis of short-term prognosis in patients with ACI Single factor logistic regression analysis shows that NIHSS score, HbA1C, MAGE, TC, LDL-c, FBG, 2 hPG, CRP, fasting insulin, HOMA-IR, history of hypertension, hyperlipidemia, diabetes, were factors affecting the short-term prognosis of acute cerebral infarction (mRS score, $p<0.05)$. Multivariate Logistic regression analysis showed that NIHSS score, HbA1C, and MAGE were the risk factors influencing the short-term prognosis in patients with ACI $(p<0.05)$, but history of hypertension, hyperlipidemia and diabetes history, were of no statistical difference with mRS in acute cerebral infarction patients (Table 5).

\section{Discussion}

The risk of acute cerebral infarction mortality in type 2 diabetic patients is more than two-fold higher compared with that in age-matched subjects. Approximately 30-40\% of ACI patients present with admission hyperglycemia either as a result of diabetes or acute stress response $e^{6,19}$. Type 2 diabetes, holds a 2-6 fold increased risk for cerebrovascular disease and stroke $^{19,20}$. Naber ${ }^{21}$ found that regardless of diabetes mellitus history, ACI patients admitted to hospital had higher mortality with higher blood glucose level than that of the normal glucose, with a significant short-term deteriorated prognosis even in the case of reperfusion. Williams ${ }^{22}$ also found that hyperglycemia after acute cerebral infarction will increase the mortality within 30 days, one year or six years. Although a number of studies have found that glucose level was associated with poor prognosis in ACI patients, the relationship between glucose excursion and short-term prognosis was not described. To determine the shortterm prognosis of acute cerebral infarction, $\mathrm{mRs}$ as an index of functional disability level has a good reliability and authenticity $^{23}$.

Glucose metabolic disorder in vascular pathological changes in DM is not only characterized by increased glucose levels, as blood glucose fluctuations between peaks and valleys is more important. HbA1c did not show any single correlation with $\mathrm{AG}$, $\mathrm{SD}, \mathrm{AUC}>180$, glycoalbumin may reflect not only short-term average glucose but also fluctuations of glucose ${ }^{24}$. Krinsley ${ }^{25}$ found that SDBG of intensive care unit patients is an independent predictor of mortality in critically ill patients. The MAGE, which has higher accuracy compared with SDBG, is considered to be golden standard representing blood glucose fluctuations; and its change does not only depend on the overall level of blood glucose, but reflects discrete trends. This study showed glucose fluctuations increased significantly in patients with ACI, when blood glucose increased, in transiently elevated glucose patients or diabetes mellitus patients. They all showed significant fluctuations in glucose. By measuring indexes reflecting daytime fluctuation: MODD SDBG and MAGE the fluctuations were more obvious in ACI patients with DM. Meanwhile, 2h PG as well as HbA1c level in ACI patients with 
DM were obviously increased compared with levels in patients without DM, which indicated that, in addition to the body's stress response causing glucose fluctuation, the development of the continuing role of hyperglycemia on cerebral infarction may have had an effect that cannot be ignored.

This study also found that ACI patients with DM had more severe dyslipidemia, which suggests that in patients with longterm hyperglycemia may have multiple metabolic disorders. Levels of HCY, HOMA- IA, FBG and CRP were significantly higher in patients with diabetes mellitus than in the other three groups, grouped according to the MAGE level. Previous studies $^{26}$ demonstrated that high HCY levels increased the incidence of people suffering from stroke, while in these patients, CRP levels increased significantly and could last for a long time. Another study of diabetic patients found a pathogenetic relationship between cerebrovascular disease and their blood glucose levels on admission to hospital ${ }^{27}$. Correlation analysis of ACI patients with diabetes mellitus demonstrated that the degree of neurologic impairment, increased HCY levels, insulin resistance, and FBG were closely related with daytime blood glucose swings. The more serious the neurologic impairment, the higher CRP, HCY levels, and insulin resistance. Clotting mechanism became disorder; hospital early cerebral ischemic hypoxia is more serious. Even in the normal range of FBG, there is a significant association between more severe strokes and higher FBG one week after the stroke ${ }^{28}$. The ACI patients with diabetes mellitus had higher NIHSS score than those without DM and, 14 days after treatment, NIHSS and mRs scores were still higher than patients without a history of diabetes, which indicated that a combination of long-term hyperglycemia or glucose metabolic disorders in ACI patients would lead to a poor prognosis. Studies have shown that glucose fluctuations had considerably more risk than sustained hyperglycemia. Goto-Kakizaki rats fed twice daily showed markedly higher number of monocytes adherent to the endothelium than those fed ad libitum, together with increased arterial intimal thickening ${ }^{29}$. Glucose levels have a greater adverse effect on neuronal cell energy regulation mechanisms than either sustained high or low glucose levels. Most of the glucose stress-modulated genes were components of the intrinsic/mitochondrial apoptotic pathway including Bcl-2, caspases and apoptosis executors ${ }^{30}$. The degree of phosphorylation and acetylation of FOXO transcription factors were different between SHG and IHG, which might be one mechanism of increased INS-1 cell apoptosis in $\mathrm{IHG}^{31}$. In Logistic regression analysis, the factors influencing the shortterm prognosis were HbA1C, NIHSS score and MAGE level, which suggests that the history of DM was not significant for the short-term prognosis. The influence of ACI may depend on the extent of blood glucose fluctuations, rather than the average glucose levels. The adverse impact $\mathrm{HbA} 1 \mathrm{C}$ levels and glucose fluctuations had on the prognosis of ACI patients may be larger than the influence of DM history. Blood glucose fluctuation may be an important risk factor for mRS. Other factors, such as blood pressure, age and $\mathrm{HbA} 1 \mathrm{c}$ cannot be completely ruled out as factors influencing patients' prognosis. Group A patients have higher age and anti-hypertension drug usage rate; the blood pressure of $85 \%$ of these patients is below or near the critical range of $140 / 90 \mathrm{~mm} \mathrm{Hg}$.

\section{Conclusions}

Blood glucose fluctuations increase in ACI patients admitted to hospital, especially within the first three days in ACI patients with T2DM. Glucose metabolism in T2DM patients with ACI have the characteristics of larger fluctuations with longer duration. Blood glucose fluctuations may have a significant influence on neurologic impairment and large cerebrovascular lesions, resulting in a poorer prognosis.

\section{ACKNOWLedgement}

This project was supported by Grant 2011ZX09307-001-08 from National Science and Technology Major Project of China. The authors thank Nurse Sulin Wang and Xiuping Xu for help managing work with all doctors.

\section{REFERENCES}

1. Yang ZJ, Liu J, Ge JP, Chen L, Zhao ZG, Yang WY. Prevalence of cardiovascular disease risk factor in the Chinese population: the 2007-2008 China National Diabetes and Metabolic Disorders Study. Eur Heart J. 2012;33(2):213-20.

2. Barrett-Connor E, Khaw KT. Diabetes mellitus: an independent risk factor for stroke? Am J Epidemiol. 1988;128(1):116-23.

3. Burchfiel CM, Curb JD, Rodriguez BL, Abbott RD, Chiu D, Yano $\mathrm{K}$. Glucose intolerance and 22-year stroke incidence. The Honolulu Heart Program. Stroke. 1994;25(5):951-7.

4. Folsom AR, Rasmussen ML, Chambless LE, et al. Prospective associations of fasting insulin, body fat distribution, and diabetes with risk of ischemic stroke. The Atherosclerosis Risk in Communities (ARIC) Study Investigators. Diabetes Care. 1999; 22(7):1077-83.

5. Capes SE, Hunt D, Malmberg K, Pathak P, Gerstein HC. Stress hyperglycemia and prognosis of stroke in nondiabetic and diabetic patients: a systematic overview. Stroke. 2001;32(10): 2426-32.

6. Baird TA, Parsons MW, Phanh T, et al. Persistent poststroke hyperglycemia is independently associated with infarct expansion and worse clinical outcome. Stroke. 2003;34(9): 2208-14.

7. Parsons MW, Barber PA, Desmond PM, et al. Acute hyperglycemia adversely affects stroke outcome: a magnetic resonance imaging and spectroscopy study. Ann Neurol. 2002;52(1):20-8.

8. Sykora M, Diedler J, Turcani P, Hacke W, Steiner T. Baroreflex: a new therapeutic target in human stroke? Stroke. 2009;40(12): e678-82.

9. Ay H, Arsava EM, Koroshetz WJ, Sorensen AG. Middle cerebral artery infarcts encompassing the insula are more prone to growth. Stroke. 2008;39(2):373-8.

10. Lachin JM, Genuth S, Nathan DM, Zinman B, Rutledge BN. Effect of glycemic exposure on the risk of microvascular complications in the diabetes control and complications trial--revisited. Diabetes. 2008;57(4):995-1001.

11. Meigs JB, Nathan DM, D'Agostino RB, Sr., Wilson PW, Framingham Offspring Study. Fasting and postchallenge glycemia and cardiovascular disease risk: the Framingham Offspring Study. Diabetes Care. 2002;25(10):1845-50.

12. Ceriello A, Hanefeld M, Leiter L, et al. Postprandial glucose regulation and diabetic complications. Arch Intern Med. 2004; 164(19):2090-5

13. Gerich JE. Clinical significance, pathogenesis, and management of postprandial hyperglycemia. Arch Intern Med. 2003;163(11): 1306-16.

14. Quagliaro L, Piconi L, Assaloni R, Martinelli L, Motz E, Ceriello A. Intermittent high glucose enhances apoptosis related to oxidative stress in human umbilical vein endothelial cells: the role of protein kinase $\mathrm{C}$ and $\mathrm{NAD}(\mathrm{P}) \mathrm{H}$-oxidase activation. Diabetes. 2003;52(11):2795-804. 
15. Brott T, Adams HP, Jr., Olinger CP, et al. Measurements of acute cerebral infarction: a clinical examination scale. Stroke. 1989;20 (7):864-70

16. Bonita R, Beaglehole R. Recovery of motor function after stroke. Stroke. 1988;19(12):1497-500.

17. The Chinese Medical Association TCion. Diagnosis of cerebrovascular disease. J Neurology. 1996;29(6):379.

18. Colman PG, Thomas DW, Zimmet PZ, Welborn TA, Garcia-Webb P, Moore MP. New classification and criteria for diagnosis of diabetes mellitus. The Australasian Working Party on Diagnostic Criteria for Diabetes Mellitus. N Z Med J. 1999;112(1086): 139-41.

19. Gray CS, Hildreth AJ, Sandercock PA, et al. Glucose-potassiuminsulin infusions in the management of post-stroke hyperglycaemia: the UK Glucose Insulin in Stroke Trial (GISTUK). Lancet Neurol. 2007;6(5):397-406.

20. Martini SR, Kent TA. Hyperglycemia in acute ischemic stroke: a vascular perspective. J Cereb Blood Flow Metab. 2007;27(3): 435-51.

21. Naber CK, Mehta RH, Junger C, et al. Impact of admission blood glucose on outcomes of nondiabetic patients with acute STelevation myocardial infarction (from the German Acute Coronary Syndromes [ACOS] Registry). Am J Cardiol. 2009; 103(5):583-7.

22. Williams LS, Rotich J, Qi R, et al. Effects of admission hyperglycemia on mortality and costs in acute ischemic stroke. Neurology. 2002;59(1):67-71.

23. D'Olhaberriague L, Litvan I, Mitsias P, Mansbach HH. A reappraisal of reliability and validity studies in stroke. Stroke. 1996;27(12):2331-6.
24. Suwa T, Ohta A, Matsui T, et al. Relationship between clinical markers of glycemia and glucose excursion evaluated by continuous glucose monitoring (CGM). Endocr J. 2010;57(2): $135-40$.

25. Krinsley JS. Glycemic variability: a strong independent predictor of mortality in critically ill patients. Crit Care Med. 2008;36(11): 3008-13.

26. Holmes MV, Newcombe P, Hubacek JA, et al. Effect modification by population dietary folate on the association between MTHFR genotype, homocysteine, and stroke risk: a meta-analysis of genetic studies and randomised trials. Lancet. 2011;378(9791): 584-94.

27. Phipps MS, Jastreboff AM, Furie K, Kernan WN. The diagnosis and management of cerebrovascular disease in diabetes. Curr Diab Rep. 2012;12(3):314-23.

28. Martin RJ, Ratan RR, Reding MJ, Olsen TS. Higher blood glucose within the normal range associated with more severe strokes. Stroke Res Treat. 2012;2012:659610.

29. Azuma K, Kawamori R, Toyofuku Y, et al. Repetitive fluctuations in blood glucose enhance monocyte adhesion to the endothelium of rat thoracic aorta. Arterioscler Thromb Vasc Biol. 2006;26 (10):2275-80.

30. Russo VC, Higgins S, Werther GA, Cameron FJ. Effects of fluctuating glucose levels on neuronal cells in vitro. Neurochem Res. 2012;37(8):1768-82.

31. Kim M, Chung H, Yoon C, et al. Increase of INS-1 cell apoptosis under glucose fluctuation and the involvement of FOXO-SIRT pathway. Diabetes Res Clin Pract. 2012;98(1):132-9. 